Michael Paolo M. Tapangco, MD

Waynn Neilsen Destriza, MD

Bernardo D. Dimacali, MD ${ }^{1,2}$

Mildred B. Olveda, MD'

'Department of Otolaryngology

Head and Neck Surgery

Ospital ng Makati

${ }^{2}$ Department of Otolaryngology Head and Neck Surgery

Far Eastern University - Nicanor Reyes

Memorial Medical Foundation

\section{Topical Cepae Extract-Heparin Sodium- Allantoin Gel versus Placebo on Hypertrophic Thyroidectomy Scars: A Randomized, Double- Blinded, Split-Scar Controlled Trial}

\begin{abstract}
Objective: Topical cepae extract-heparin sodium-allantoin gel is one of the many non-invasive scar treatments available to improve the appearance and physical attributes of scars. This paper aims to compare the effectiveness of topical cepae extract-heparin sodium-allantoin gel versus placebo based on appearance and physical attributes of hypertrophic thyroidectomy scars.
\end{abstract}

\section{Methods:}

Design: Randomized, double-blinded, split-scar controlled trial

Setting: Out-Patient Department of a tertiary government hospital

Patient: 20 patients with hypertrophic thyroidectomy scars had each side of the scar randomly assigned treatment with topical extract cepae-heparin sodium-allantoin gel or placebo (glycerine gel). Each product was applied two times daily for six weeks, and scars were evaluated prior to initiation of treatment and after six weeks by patients and one observer. Pre- and posttreatment photo documentation and scar evaluation using a local language translation of the Patient and Observer Scar Assessment Scale (POSAS) were completed for each side of the scar.

Results: There was no significant difference in effectiveness of topical cepae extract-heparin sodium-allantoin gel versus placebo for both the patient scale $(p=0.91)$ and observer scale $(p=$ $0.87)$ in appearance and physical attributes of a thyroidectomy scar.

Conclusion: Topical cepae extract-heparin sodium-allantoin gel was not proven to be superior to the placebo as scar therapy in all parameters assessed by the Filipino translation of POSAS. The small sample size, duration of hypertrophic scar, duration of treatment, and validity and reliability of the Filipino translation of POSAS may have affected our results; and periodic subjective and objective assessments with multi-observer evaluation of scars and pre- and post- treatment photographs may be considered for further studies.

Keywords: Topical Cepae Extract-Heparin Sodium-Allantoin Gel, Glycerine, Patient and Observer Scar Assessment Scale, thyroidectomy scar, scar

Head and neck surgical scars may be difficult to conceal, and thyroid surgery is a common head and neck procedure whose scar may create stigma for the patient. The first two months of scar maturation are especially associated with a tendency for hypertrophic scar development. ${ }^{1}$ The disfiguring appearance of the linear hypertrophic scar in the neck can produce low self- 
esteem and social isolation which can significantly interfere with the psychological well being of the person afflicted.

There are numerous invasive and non-invasive treatment options to improve scar appearance, including intra-lesional corticosteroids (triamcinolone), topical silicone gel, compression or pressure therapy and surgical scar excision or revision, radiotherapy and cryotherapy. ${ }^{1,2,3}$ Treatment with topical cepae extract-heparin sodium-allantoin gel has been claimed to have special value in hypertrophic scars due to its anti inflammatory activity, fibroblast anti-proliferative activity, inhibition of proteoglycan and collagen formation, loosening of collagen structure and improvement of scar elasticity. ${ }^{4}$

However, there is conflicting evidence on the effectiveness of this preparation in improving scar appearance. Some reported improvement in the color of scar alone $e^{1,2,3,4}$ while others claim no improvement in scar appearance. ${ }^{2,3}$ This study aims to assess the effectiveness of cepae extract-heparin sodium-allantoin gel versus placebo in the treatment of thyroidectomy scars using a Filipino translation of the Patient and Observer Scar Assessment Scale (POSAS). ${ }^{5}$

\section{METHODS}

\section{Study Design and Setting}

A randomized, double-blinded, split scar controlled trial was conducted between January and June 2010 at the Out-Patient Department of the Ospital ng Makati, a tertiary government hospital in the Philippines.

\section{Participants}

With institutional ethics committee approval, 56 patients with hypertrophic scars were recruited from the thyroidectomy patients of the primary investigator. Inclusion criteria were: age between 18-60 years old, total or subtotal thyroidectomy or thyroid lobectomy through a transcervical incision performed by a single surgeon, benign thyroid pathology, hypertrophic scar, and at least four weeks healing after surgery. Excluded were patients under treatment with topical antibiotics or topical corticosteroids, thyroid malignancy, uncontrolled diabetes, autoimmune disorders, plans of pregnancy or current pregnancy or breastfeeding, and patients with known sensitivities to any ingredients of the test products. With informed consent, 20 patients who were eligible for the study were randomly assigned patient identification numbers and frontal-view photographs of the scars were taken.

\section{Procedures}

Prior to the start of the study, an independent nurse prepared 10 grams each of cepae extract-heparin sodium-allantoin gel (Contractubex', Merz Pharmaceuticals, Frankfurt, Germany) and placebo (glycerine gel) in paired identical containers. The paired containers had color-coded red (right) and blue (left) labels. The topical cepae extractheparin sodium-allantoin gel was randomly assigned to either right (red) or left (blue) container. The test drug and placebo shared the same physical attributes, both being colorless and gel-like. The samples were kept in identical envelopes and were sealed. Envelopes and sample containers were also number-coded and were given randomly to the participants by the independent nurse to ensure that both the patient and the observer were blinded.

At the start of the study, pre-treatment assesments were separately performed by each patient and one observer using the Patient and Observer Scar Assessment Scale Version 1.0 whose validity and reliability had been previously established (POSAS v1.0, Draaijers et al., 2004). ${ }^{5}$ (Appendix A) The patients used a Filipino translation of the scale which was pre-tested prior to the study and approved by the ethics commitee. (Appendix B) Pre-treatment photographs were likewise taken for documentation and comparison. After completing the scales and photographs, instructions and follow-up schedules with colorcoded containers containing the test drug and placebo in numbercoded envelopes were given each patient by the assistant. Patients were instructed to divide the scar in the midline by an imaginary line from the mentum to the sternal notch. Gel was applied in a layer of $1 \mathrm{~mm}$ by simple spreading on the skin towards the periphery and application to each half of the scar was performed twice a day, guided by the color-labeled containers and instructions in each envelope. To prevent diffusion of test drug and placebo, patients were instructed to start the application approximately $1 \mathrm{~cm}$ or 1 finger breath away from the center or the imaginary line drawn from the mentum to the sternal notch towards left or right side scar. $1 \mathrm{~mm}$ of gel was rubbed continuously into each half-scar until it dried up, from the first day after initial assessment for six weeks. Patients were advised follow-up every two weeks, to contact the primary investigator in case of untoward side effects, and to stop treatment immediately if signs of allergy or adverse drug reactions occured. At the end of the 6-week treatment period, each patient and the same observer separately accomplished the Filipino translation of the POSAS for the second time. Post-treatment photographs were also taken.

\section{Outcome Measures}

The primary outcome measures were the subjective observations of patients and the lone observer with regards to the appearance and physical attributes of the scar at baseline and after six weeks of treatment. The normalization or the change in the scar in terms of pain, pruritus, color, stiffness, thickness, and irregularity were the specific parameters assessed in the patient scale while the vascularity, 


\section{ORIGINAL ARTICLES}

pigmentation, thickness, relief, and pliability were considered in the observer scale. Pre and post-tratment photographs were also used to compare scar appearance.

\section{Data Analysis}

After completion of data collection, decoding of the collected data was performed. Data were recorded and analysed using Statistical Package for Social Sciences (SPSS) version 17.0 for Windows (IBM, Armonk, NY, USA). The T-test ( $p=0.05$ ) was used to test for any significant differences of the total POSAS scores pre- and post-treatment.

\section{RESULTS}

Of the 56 subjects initially considered, 20 were finally included in the study, making a total of 40 split-scars. There were 18 women and 2 men, with a mean age of 43.5 years old (range 29 to 60 years old). All of the patients claimed good compliance with the treatment protocol and reported no adverse reactions.

Initial visit patient scales yielded a mean score of 5.98 on both sides while observer scales had mean scores of 5.65 on both sides. At the end of the 6-week treatment period, the means score for the patient scales was 3.08 for the placebo and 3.28 for the test drug while on the observer scale, the mean score for the placebo was 3.71 and for the test drug was 3.84. Using the t-test, there was no significant difference pretreatment and post treatment between test drug and placebo $(p=0.91)$ in either the patient scales or observer scale $(p=0.87)$.

\section{DISCUSSION}

Hypertrophic scars are among the major concerns of thyroidectomy patients. The incidence of hypertropic scars following surgery is about 40 to $70 \% .{ }^{6,7}$ In contrast to keloids, which extend beyond the borders of the original injury, hypertrophic scars remain confined to the borders of the original wound and most of the time retain their shape. ${ }^{78}$ The collagen fibers in this type of scar are oriented somewhat parallel to the long axis of the scar. ${ }^{8}$ Based on a classification by Mustoe, a linear hypertrophic (e.g., surgical/traumatic) scar is described as a red, raised, sometimes itchy scar confined to the border of the original surgical incision that occurs within weeks after surgery. ${ }^{3}$

Numerous non-invasive techniques to address scars have been described. Silicone gel using polyethylene or polyurethane is a safe and effective management option for hypertrophic scars and keloids. ${ }^{1,6,7}$ Compression or pressure therapy recommends that pressure be maintained between 24 and $30 \mathrm{mmHg}$ for 6 to 12 months to be effective.' Intralesional corticosteroids using triamcinolone are the first-line therapy for treatment of keloids and second-line therapy for treatment of hypertrophic scars if other non-invasive treatment options have failed. ${ }^{1}$

Topical cepae extract-heparin sodium-allantoin gel has been claimed to have special value in hypertrophic scars due to its anti inflammatory activity, fibroblast anti-proliferative activity, inhibition of proteoglycan and collagen formation, loosening of collagen structure and improvement of scar elasticity. ${ }^{48}$ At least three months of continous use is recommended by the product literature, but one study only used it for 1 month ${ }^{11}$ while other studies had application periods ranging from 3 to 12 months. ${ }^{13}$ Conflicting results have been reported and no true consensus has been established. A study by Beuth concluded that extract cepae gel application proved to be significantly superior to corticosteroid application in terms of safety and efficacy. ${ }^{4}$ In another study, the clinical course of scar development was rated as "very good" or "good" in more than $90 \%$ of treated thoracic surgery patients. ${ }^{8}$ Extract Cepae was found to be more effective in improving scar color but statistically ineffective in improving scar height and itching., 10 Another study comparing topical cepae extract, heparin, and allantoin gel preparation with no treatment in thoracic scars concluded that the rating was "good" and "very good" in $84 \%$ of treated cases, compared to $59 \%$ of untreated cases." Other studies have contrary findings, concluding for instance that extract cepae gel did not improve scar cosmesis or symptomatology when compared with a petrolatumbased ointment among surgical scars, ${ }^{10}$ or that topical cepae extract gel was ineffective in improving scar erythema and pruritus in patients who underwent Moh's Surgery. ${ }^{11}$

Our study showed no significant difference between test drug and placebo in the comparison of changes in mean scores. This suggests that topical cepae extract-heparin sodium-allantoin gel was no better than placebo in improving the appearance of hypertrophic thyroidectomy scars in our study.

The significant improvement noted in the placebo group may be attributed to the hydrating effects of glycerine. Glycerine gel is often used as a lubricant for nasogastric or endotracheal tube insertion. Like mineral oil, hydrating lotions and petrolatum-based ointments, glycerine may promote moist healing and rapid epithelialization, thereby decreasing hypertrophic scar formation. ${ }^{12}$ Having said that, the midlines between right and left sides of the scars may have been affected by various degrees of diffusion from either side, or not at all, and yet appeared unremarkable. Perhaps neither test drug nor placebo really made a difference after all?

That this study did not prove cepae extract-heparin sodium-allantoin gel to be more effective than placebo in improving scar appearance may also be attributable to the small sample size. The duration of the 
hypertrophic scar at the time of initiation of the study as well as duration of treatment could also affect results, and a longer period of application of the test drug in accordance with product recommendations may be implemented in future studies. The validity and reliability of the Filipino translation of the POSAS, although pretested, are also limitations to this study. Periodic subjective and objective assessments aside from baseline and post-treatment subjective assessments, and multiobserver evaluation of scars and pre- and post- treatment photographs can also be included among the parameters to consider for further studies.

\section{APPENDIX A}

Patient Code no: $\quad$ Week number $\bigcirc 0 \bigcirc 2 \bigcirc 4 \bigcirc 6$

\section{Observer Scar Assessment Scale}

\section{RIGHT}

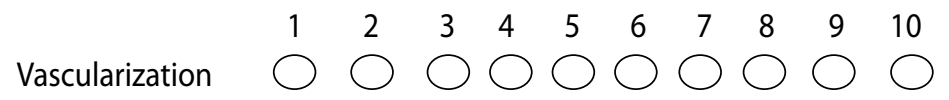

Pigmentation $\bigcirc \bigcirc \bigcirc \bigcirc \bigcirc \bigcirc \bigcirc \bigcirc \bigcirc \bigcirc$

Thickness $\bigcirc \bigcirc \bigcirc \bigcirc \bigcirc \bigcirc \bigcirc \bigcirc \bigcirc \bigcirc$

Relief $\bigcirc \bigcirc \bigcirc \bigcirc \bigcirc \bigcirc \bigcirc \bigcirc \bigcirc \bigcirc$

Pliability

TOTAL OBSERVER SCALE

Patient Code no: $\quad$ Week number $\bigcirc 0 \bigcirc 2 \bigcirc 4 \bigcirc 6$

Observer Scar Assessment Scale

LEFT

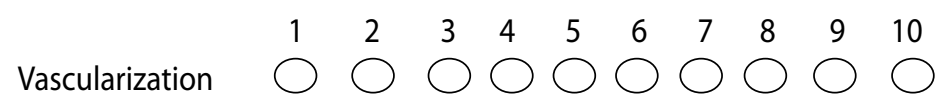

Pigmentation $\bigcirc \bigcirc \bigcirc \bigcirc \bigcirc \bigcirc \bigcirc \bigcirc \bigcirc$

Thickness $\bigcirc \bigcirc \bigcirc \bigcirc \bigcirc \bigcirc \bigcirc \bigcirc \bigcirc \bigcirc$

Relief $\bigcirc \bigcirc \bigcirc \bigcirc \bigcirc \bigcirc \bigcirc \bigcirc \bigcirc$

Pliability $\bigcirc \bigcirc \circ \bigcirc \bigcirc \bigcirc \bigcirc \bigcirc \bigcirc \circ$
APPENDIX B

Patient Code no: Weeknumber $\bigcirc 2 \bigcirc 4 \bigcirc 6 \bigcirc 8$

\section{Patient Scar Assessment Scale}

Please answer this scale according to your scar characteristics on the RIGHT side.

Maaari po bang sagutan ninyo ang mga tanong ukol sa inyong peklat sa bahaging KANAN

No, No complaints Yes, worst imaginable

Walang reklamo Meron, pinakamatindi

Is the scar painful? $\bigcirc \bigcirc \bigcirc \bigcirc \bigcirc \bigcirc \bigcirc \bigcirc \bigcirc \bigcirc$ Masakit ba ang peklat?

Is the scar itching?

Kumakati ba ang peklat?

No, as to normal skin Yes, very different

Wala kung ikukumpara Oo, malaki pagkakaiba

sa normal na balat

Is the color of the scar

different?

Nagkaiba ba ang kulay

ng peklat?

Is the scar more stiff? Mas matigas ba ang peklat?

Is the thickness of the

scar different?

Nagkaiba ba ang

kapal ng peklat?

Is the scar irregular? $\bigcirc \bigcirc \bigcirc \bigcirc \bigcirc \bigcirc \bigcirc \bigcirc \bigcirc$ Pantay-pantay ba ang peklat?

TOTAL PATIENT SCALE 
ORIGINAL ARTICLES

Philippine Journal Of Otolaryngology-Head And Neck Surgery

Vol. 27 No. 2 July - DeCEMBER 2012

PJOINS

Patient Code no:

Week number $\bigcirc \bigcirc \bigcirc \bigcirc 6 \bigcirc 8$

\section{Patient Scar Assessment Scale}

Please answer this scale according to your scar characteristics on the LEFT side.

Maaari po bang sagutan ninyo ang mga tanong ukol sa inyong peklat sa bahaging KALIWA

No, No complaints

Walang reklamo

Yes, worst imaginable Meron, pinakamatindi
Is the scar painful? $\bigcirc \stackrel{1}{\bigcirc} \bigcirc \bigcirc \stackrel{3}{\bigcirc} \bigcirc \stackrel{5}{\bigcirc} \bigcirc$ Masakit ba ang peklat?

Is the scar itching?

Kumakati ba ang peklat?

No, as to normal skin Wala kung ikukumpara Yes, very different sa normal na balat

Is the color of the scar different? Nagkaiba ba ang kulay ng peklat?

Is the scar more stiff? Mas matigas ba ang peklat?

Is the thickness of the scar different? Nagkaiba ba ang

kapal ng peklat?

Is the scar irregular? Pantay-pantay ba ang peklat?

TOTAL PATIENT SCALE

\section{ACKNOWLEDGEMENTS}

The authors would like to thank the following: Dr. Alberto F. Calderon and Dr. Howard Enriquez, who critically reviewed the study proposal; Ms. May Legaspi, for acting as the independent nurse for blinding of both subjects and investigators; Drs. Angel Cruz-Daylo, Carina Glorioso, Ardie Dizon, Lorelyn Dino, and Elaine Lagura, for providing and caring for the study participants, and the patients who actively participated as subjects for this trial.

\section{REFERENCES}

1. Al-Attar A, Mess S, Thomassen JM, Kauffman CL, Davison SP. Keloid pathogenesis and treatment Plast Reconstr Surg. 2006 Jan;117(1):286-300.

2. Reish RG, Eriksson E. Scars: a review of emerging and currently available therapies. Plast Reconstr Surg. 2008 Oct;122(4):1068-78.

3. Mustoe TA, Cooter RD, Gold MH, Hobbs FD, Ramelet AA, Shakespeare PG, et al.; International Advisory Panel on Scar Management. International clinical recommendations on scar management. Plast Reconstr Surg. 2002 Aug;110(2):560-71

4. Beuth J, Hunzelmann N, Van Leendert R, Basten R, Noehle M, Schneider B. Safety and efficacy of local administration of contractubex to hypertrophic scars in comparison to corticosteroid treatment. Results of a multicenter, comparative epidemiological cohort study in Germany. In Vivo. 2006 Mar-Apr;20(2):277-283.

5. Draaijers LJ, Tempelman FR, Botman YA, Tuinebreijer WE, Middelkoop E, Kreis RW, et al. The patient and observer scar assessment scale: a reliable and feasible tool for scar evaluation. Plast Reconstr Surg. 2004 Jun;113(7):1960-1965.

6. Edriss AS, Mesták J. Management of keloid and hypertrophic scars. Ann Burns Fire Disasters. 2005 Dec;18(4):202-10.

7. Chan KY, Lau CL, Adeeb SM, Somasundaram S, Nasir-Zahari M. A randomized, placebocontrolled, double-blind, prospective clinical trial of silicone gel in prevention of hypertrophic scar development in median sternotomy wound. Plast Reconstr Surg. 2005 Sep;116(4):1013-20.

8. Willittal GH, Heine $\mathrm{H}$. Efficacy of Contractubex gel in the treatment of fresh scars after thoracic surgery in children and adolescents. Int J Clin Pharmacol Res. 1994; 14(5-6):193-202.

9. Hosnuter M, Payasli C, Isikdemir A, Tekerekoglu B. The effects of onion extract on hypertrophic and keloid scars. J Wound Care. 2007 Jun;16(6):251-4.

10. Chung VQ, Kelly L, Marra D, Jiang SB. Onion extract gel versus petrolatum emollient on new surgical scars: prospective double-blinded study. Dermatol Surg. 2006 Feb;32(2):193-7.

11. Jackson BA, Shelton AJ. Pilot study evaluating topical onion extract as treatment for postsurgical scars. Dermatol Surg. 1999 Apr;25(4):267-9.

12. Maragakis M, Willital GH, Michel G, Görtelmeyer R. Possibilities of scar treatment after thoracic surgery. Drugs Exp Clin Res.1995;21(5):199-206.

13. Dyakov R., Petrova M., Tzolova N., Argirova M., Treatment of superficial burns, post-burn scars, and keloids with Contractubex ${ }^{\oplus}$ gel. Annals Of Burns And Fire Disasters - 2002Jun(40) - N. 2 